\title{
Uşak ili koşullarında devekuşu civcivlerinde büyüme ve yaşama gücü
}

\author{
Zehra AKINCI', İsmail BAYRAM² \\ 1 Alyon Kocitepe linversilesi, Veteriner Falkültesi. Zootekni Anabilim Dalt. Afyon; = Alyon Kocatepe Liniversilesi. Vecteriner \\ Fakïllesi. Hayvan Besleme ve Beslenme Hastahkları Anabilim Dalı. Alyon
}

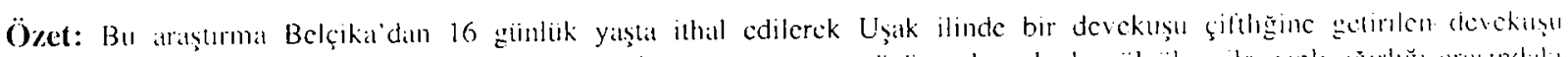

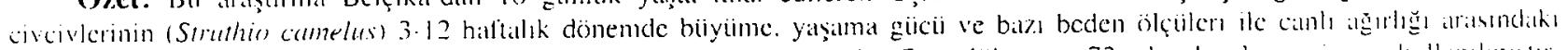

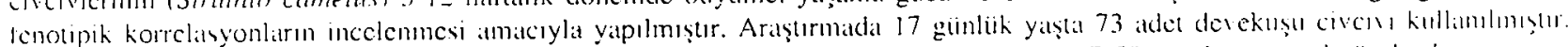

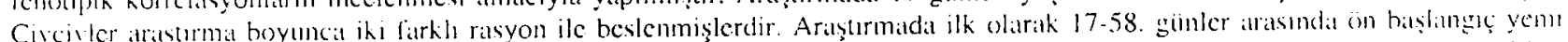

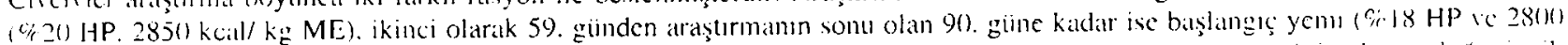

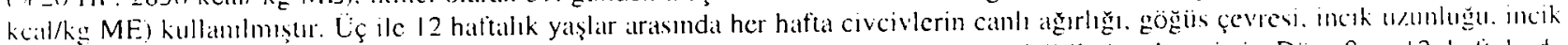

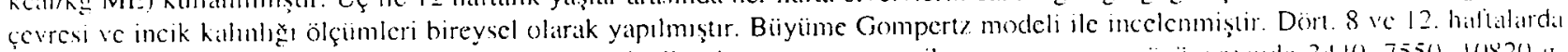

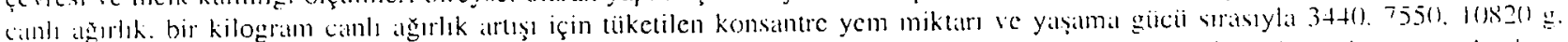

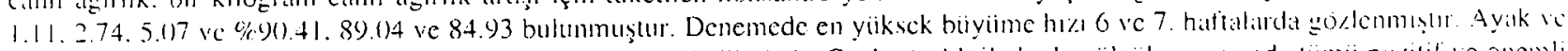

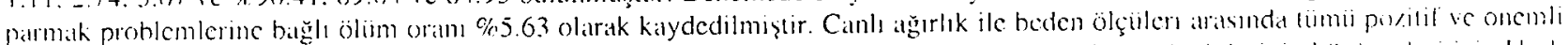

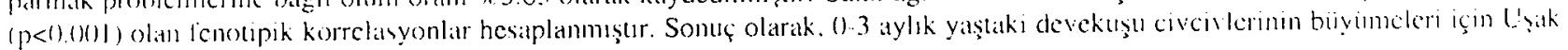

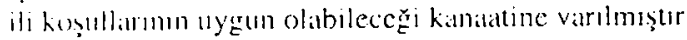

Anathlar kelimeler: Biiyiime. devekușu. fenotipik korrelasyon. yaņama giocii

\section{Growth and survival rate of ostrich chicks in Uşak province}

Summary: This study was conducted in order to insestigate the growth, survivat rate and phenotypic corrclations helween the hody weight and rome body measurements from 3 to 12 wecks of age of ostrich chicks (Struthio comelers) which were brought 10 :

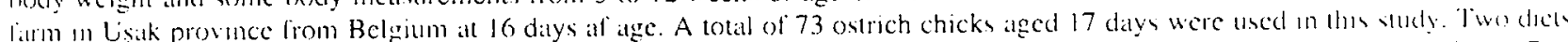

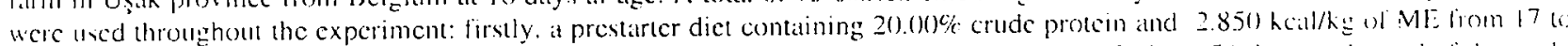
58 davs of atge, secondly, a stater diet containing $18.00 \%$ crude protcin and $2.800 \mathrm{kcal} / \mathrm{kg}$ ME from 59 days 10 the end of the study (9) days of age). Individual body weights and circumference of chest, the length. circumferenec and thick ties of metaltilsus were reconded weckly from 3 to 12 weeks of are. The growth curves of birds were evaluated by the Gompert7 cyuation. Meall body

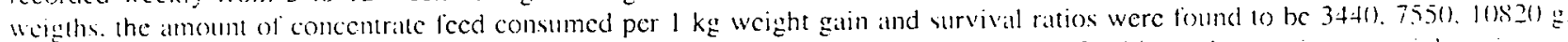
1.11. 2.4. 5.07 and 90.41 .89 .04 and $84.93 \%$ at 4.8 and 12 weeks of age. respectively. In this study. maximum weight gain wit ohserved all 6 and 7 wecks of are and mortality related to leg and toc disturbance was recorded als 5.63 per cont. All positive and

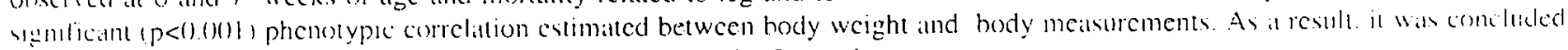
that ( ) ith province could be sultible for growth of chicks aged $0-3$ months.

Key words: Growh. ostrich, phenotypic correlations, survivat rate

\section{Giriş}

Devekuşu ilk ke\% $1880{ }^{\circ}$ li yıllarda Güney Alrika da liiyleı için eveiltilmiş ve yetiştirilmeye haşlanmışur. Dalha sonta liiy kalitesi yüksck devekuşu elde etmek amacula scleksiyon çalışmalarma başlanmuşur. Fvciltikıen Kisa sure sonral (1880\%li yllarm sonunda) Kuzey Amerika. Avustralya ve Avrupa ya götürümiş ve başarılı şekilde yetişirilmişiti. Ancak. I. Dünya Savaşı srasindal bu iblkclerde clde edilen devekuşu tiiyuinuin pazarlamasında ciddli bir darboğazla karşlașllmış ve oralarda devekuşu

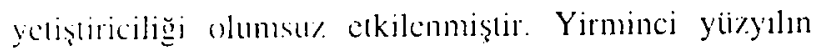
somralimanda $\left(1980^{\circ} \mathrm{li}\right.$ ynlarda) Amerika Birleşik Devkelleri. Avustralya ve Avrupa da devekuşu yetiştiriciliği oncm kitanmışur. Onceleri yetiş̧irme amacı tiiy verinsi iken zamanla et ve deri verimi öncelikli hale gelmiştir.
Devekuşu ürünlerine olan lalep ẹenelde değişken hir yapı göstcrmektedir. Devekuşu yetiştiricilig̣i äcllikle Giuncy Afrika'da tarmm innenli hir kolu haline gelmislit. Amerika Birleşik Devlelleri. Zimbahwe. Israt. Ineillere Avustralya ve diğger birçok ülkede ise devekusu ye tişliriciliğ yay ğmlaşmakladır $(1,3.4 .1 .4)$.

Devekuşunda dölverimi, hesi perlormanıs ve katkils kalitesi yüikscktir. Ayruca. devekuşu unun sure dammslik olarak kullannlabilmekledir. Boylece. bir hayvindan hayat boyunca elde edilen toplam verim yiksck of

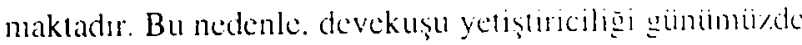
ilgi çeken bir yeliştricilik halindedir 25.5 .6 .24$)$. Diğel eveil hayvan ellerine göre daha yumuşak ve lexelli olan devekuşu eti daha a\% oranda kolesterol ve yas ig de daha farla protein içermesi nedeniyle de. yuikscek liyallara alles 
hulabilmekledir. Devekuşu derisi yumuşak. esnek ve dayanıklıhı̆ (1.18).

Diinyada henï/ yeni tammnakta olan devekuşu Afrika kılasımm iklim ve hilki örtïsii ģartlarma uymuş bir halyandır. Bu şarlardan farklı olan bölgelere götiiriilmekte. huralarda da yetiştirilnektedir. Devekuşunun çillik koşullarmalaki verim dìzeyleri ve bazı yctiştirme sorunlan ìzerinde araşumalar yapılmakıadır. En çok yenşstuldiợ Güncy Alrika'da bile yumurtaların ancak \%50 sinden civcir alnabildiğ ve civeivlerin sadece \%40\%mn kesim yaşına ulaşlabildiği. bu nedenle de rckuşu y'tiştiriciliğinin gelişiminin önünteki en önemli sorunlarm kuluçka ve civciv büyütme olduğu bildirilnektedir (8.9.17.22). Devekuşu civcivlerincle ilk 3 aylık donem oldukf̧a önemlidir $(12,19,20)$. Bu dönende bakım ve besleme koşullarına özen gösterilmelidir (1.3.17). Sluis (25). hir yaşına kadarki dönemde yaşama guicüui \%70). Deening ve ark (11) ilk iiç aylık yaşama giiciinuiu \%.66.7. Smith ve ark (26) ile Sell (23) isc

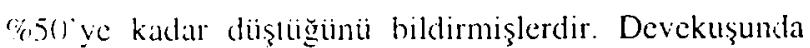
biiyume izclliğ birçok araşturnada incelenmiştir (1,20). Devekuşu civcivleri çok hareketlidirler. Bu nedenle haciak broukluklan bunlarda yaşama gücuinü f̧ok önemli diizcyde crkiler. Devekuşu civcivlerinde en sik görülen bacak bo\%ukluklanmm tibiolarsus ve matatarsus'un lakrale dönncsi, parmak dönmesi, perosis, raşitik bozukluklar olduğ bildirilmiştir $(7,23,26,28)$.

Devekuşunun ba7.ı beden ölçiileri ile canlı ağırliklam, deri yiizey alan ve yumurta verimi gibi bazı ozellikleri arasunda önenli ilişkiler hesaplanmıştur (12,26)

Türkiye゙ de Tarım ve Köyişleri Bakanlığı'nun devekuşuna ithal izni vermesiyle 1995 yılından itibaren devekuşu çifulikleri kurulmaya başlanmıştır. Bu dönemi i\%leyen süreçte özllikle damızlık civciv satışının yuiksek kàanç sağlaması ve kurulan işletmelerin hemen kuluçka kesislcrini kurup civciv satı̧̧na başlamaları jle pazar paylanın reklannla arturma girişimleri sonucu devekuşu ycliş̧rmck oldukça tarla ilg̣i çckniştir.

Türkiyède çok yeni olan bu yetiştiricilik alanındaki laaliyellerde bilgi ve lecrube eksikliğbine bağlı olarak bazı sorunlan görülmektedir. Türkiye de faaliyet gösteren işlemelerde elde edilen civcivlerin yanısıra dı̧ ülkelerden de civciv ithali yapılmaktadır. Bugün devekuşu yetiştiriciliggi yapılan biitün ülkelerde bu hayvanlarm verin dui\#yleri ve yeliştirme problemleri ïzerinde araşturmalar sümekledir ve Türkiye de de yetiştiricilerin bu konularda hilgilendirilmesi gerekmekledir.

Bu araşurmada Bclçika dan 16 güunlük yaşı ithal edilerck Uşak ilinde bir devekuşu çiftlið̧ine getirilen civ- civlerin 12 haftalsk yaşa kadar bijyiine ve yạ̦ama gatiçlerinin incelenmesi. baz heden ölçuleri ble beten ağ arasindaki fenotipik korrelasyonlanm hesaplanmasi anaçlanmıştır

\section{Materyal ve Metot}

Araştırmanın hayvan maleryalini Bclçika dă uçak. la getirilen 16 günliik 7.3 devekuşu circivi oluşurmuşur. Araşurma Uşak ilinde özel bir devekuşu işle:mesunde ckim-aralık aylarmda yürüitulnuișiuit.

Civcivlerin barmdımlmass için genenş bir kapall alà nun bir kısnunda civciv bölmesi olışlurulmus ve geriye kalan kısın civeivlerin rahat hareket emeleri ue cogess yapabilmesi amacıyla kullanılmuşur. Civcivler 17.30. günler arasunda civciv bölmesinde oluşlurulan 6 kioçiik bölmede tutulmuş, daha sonma bölmeler kalduralarak grup. lar birleştirilmiştir $(10,11)$. Civcivler 4 haftalik olunciaya kadar civciv bölmesindeki ortam sicaklng $28^{\circ} \mathrm{C}$ de lu tulmuş, izleyen haftalarda sicaklık hattada ? 2 şer derece olmak üzcre $24^{\circ} \mathrm{C}$ ye kadar diișiriilmiş ve bu sıcaklıklal sabit tutulmuştur. Civciv bölmesinin zenmmine tenti\% kun serilniş, tabanı temi\% tumak için günliik olarak kmizlik yapılnuştu $(18,23,26)$. Civcivler 4 haltallek olumciayal kadar civeiv odasinda tululmuş. dahal soma mevisim sıcaklığınn düşuik olması dikkatc almarak orlam s]caklığmın elverişli olduğu zamandarda giindüzleri gِezinme alanına çıarılmıştır. Ilk güinler kısal sürclerle dışaryya çıkarılan civeivlerin sonraki giinlerde gecrinme alanındaki kalma sürcleri arturlarak guineşli havalarda hava koşullarmmn elverdiği olçuide saal 1100 -15.00 arasunda dışarda kalnalarma izin verilnuş̧ar. Hayvamlanal 8:16 saat aydinlık:karanlık foloperiyodu uyggulanmıs. aydinlatma $8.00^{\circ} \mathrm{de}$ başlatılmışur (11)

Civcivler getirildikleri günden itibaren kontrol aluna alınmış, civcivlerin sağlık clurumu ve olimmler kalydectilmiştir. Taşınma stresinin etkisi dikkale alınarak ilk canhl ağırlık ve beden ölçülerinin tespitine $2 \mathrm{i}$ ggünluikle haş lanmıs, 3, 4 ve 5 . haftalarda bircr halfia ara ile. bundan sonra ise iki haftada bir olmak izere 7.9. 11 ve 12. haf-

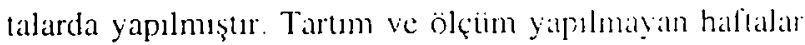
(6. 8 ve 10. haftalar) için interpolasyon vapulunş̧u (27). Araşurmaya başlamadan innec hayvanlar numaanalanmuş ve veriler bireysel olarak alımmışır. Becten ölęimleri aşağıda lanmlanan bölgelerden alımmı̧̧ur (16)

1. Göğüis çevresi: Dorsalde throcal omurlarm ïæcrinden. yanlarda kaburgalar ve altla sternumun allundan geçecek sekilde göğüs çevresi jolçümüi (thorax’un çevesi).

2. Incik uzunluğu: Tarsonetalarsus" un u/unluğu.

3. Incik çevresi: Tarsomelalarsus kemiğinin orlasmdan (incigin orlasından) alınan çevre 
4. Incik kalınlığı: Tarsometatarsus kemiğinin or-lasmolan alunan nedio-laleral çap.

Tartumlar için 0.10 g’a hassas clekrtronik bir terazi, göğuis ve incik çevresi ile incik uzunluğunun belirlenmesi için ölçü şeridi kullanılnışur. Incik kahınhı̆̆nnn ölçümü için $0.01 \mathrm{mn}$ yo hassas kompas kullamılmışur.

Civcivler 1758 . ginler arasinda \%20 ham protein (HP) ve $2850 \mathrm{kcal} / \mathrm{kg}$ metabolik enerji (ME) içeren ön haşlanģ yemi. 59-90). günler arasmanda \%18 HP ve 2800 $\mathrm{kcall} / \mathrm{k}$ : ME içeren başlanğ halla hay'anlara kaba yem hiç verilmemiştir. Bundan sonraki dönemde mevsimin sonbahar-kış olması nedeniyle hayvanlara taze yeşil yem verilememiş ve her güin çok a\% miklarda kuru yonca yaprağ verilmiştir (6.11.21). Hayvandara yem ve su ad libitum olarak verilmişlir. Yemdon yararlanma değeri kuru yonca çok a\% miklarda ve larulmadan verildiğ için kaba yem için hesiplanmamıs. sadece tiikelilen konsantre yem için hesaplannmuşur.

\section{İtatistik analizler}

Regresyon modeli ile (Gomperk modeli) biiyüme cğrileri oluşturulmuştur (10.14,26).

$$
\mathrm{Y}_{\mathrm{t}}=\Lambda \cdot \operatorname{Exp}|-\operatorname{Exp}(-\mathrm{B} \cdot(\mathrm{L}-\mathrm{C}))|
$$

Yı: Incelencn özellik (ciml ağırlık. göğiis çcvresi, incik urunluğ incik çevesi ve incik kahnlığı)

a.b.c = Regresyon katsayss terimleri

$1=$ Yaş (haltia)

Fxp: Maltematiksel iistsel lonksiyonu temsil cmektedir.

Devekuşu civcivlerinin göğüs çevresi, incik uzun luğu, incik f̧evresi ve incik kalınlığ ile ilgili istatistik degerlerin ve canl ağırlık değgerleri jle beden ölçüleri arasindiki fenotipik korrelasyonlann hesaplanmasinda SPSS pakeı progranı kullanılmuşur

\section{Bulgular}

Devekuşu civeivleri için elde edilen caunl ağ canlı ağırlık kazancı, yem tiiketini. yemden yararlamma değeri ve yaşama guicuine ait jslatistik değerler Tablo l'de verilmiştir.

Devekuşu civeivlerinde 3. hattada ontalama canlı ağırlık 2550 g ve yaşama gücii \%97.26. 12 hallactal isc canlı ağnllk 10820 g ve yaşama guicui \% 84.93 hulummuş-

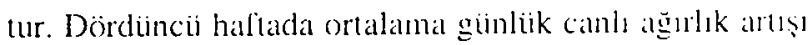
126.58 g ve ortalana günlik yem liikctimi 140 g ve yemden yararlanma değeri 1.11 olarak kespit edilmişijr. En yüksek ortalama günliik canlı ağırlık artı̧ı 6. haftada 158.98 g ve 7 . haltada 163.66 g olarak icspil colilirken. sonraki dönemlerde daha düşuk bulummuşar. Yem liiketimi ve yemden yararlanma degerinde 4. haltadan itiharen giderek artıs tespil edilmis, 12 haftalık yașta bu de gerler sırası ile $608.0 \mathrm{~g}$ ve 5.07 olarak belirlemmiştir.

Devekuşu civcivlerinin göğtis f̧evesi. incik u\%un luğu. incik çevresi ve incik kalunlığ deg gerleri Tablo ?’de verilmiştir

Ụ̈ haftalık yaşlaki civcjvlerin gögüis f̧corsi. mcik uzunluğu, incik çevresi ve incik kalmulığ değgerleri srastyla $37.75 .12 .28,5.29 \mathrm{~cm}$ ve $1.3 .27 \mathrm{~mm}$ dial lespil edilmiştir. Civeivlere ait beden ölçüleri hayvanlar hỉyüiduikçc arınış. 12 haffalık yaşla aynı stra jle 6/.32. $24.60,8.22 \mathrm{~cm}$ ve $20.3 .3 \mathrm{~mm}$ olarak helirlenmiçit

Canlı ağılık. gögüis çcvresj. incik uzunluğu. incik çevresi ve incik kalhnhğgna ait regresyon modeli sonuçata Tablo 3 ile Şekil l'de gösterilmiştir.

Oluşurulan regresyon modelinin belirtme kall sayları canlı ağılık. goğgus çevresi. incik wamluğu. incik çevresi ve incik kallunlığ için ( $\left.\mathbb{R}^{2}\right)$ smalsı ile 0.9952. 0.9995. 0.9994.0.9997 ve 0.9916 olarak hesaplammuşur

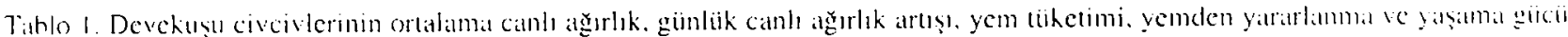
deserleri.

Tahle I. Meitn body weight, daily weight gain, feed consumption. feed conversion ratio and liveability values of westrich chichs.

\begin{tabular}{|c|c|c|c|c|c|c|c|c|c|}
\hline \multirow[t]{2}{*}{$\begin{array}{l}\text { Yars } \\
\text { (halftal) }\end{array}$} & \multirow[b]{2}{*}{11} & \multicolumn{3}{|c|}{$\begin{array}{c}\text { Canlu agrolik } \\
\left(\begin{array}{c}g \\
g\end{array}\right)\end{array}$} & \multicolumn{2}{|c|}{$\begin{array}{c}\text { Canlı ăğılık artuşı } \\
\text { (g/hay'an/güiı) }\end{array}$} & \multirow{2}{*}{$\begin{array}{l}\text { Konsantre yem } \\
\text { liikctimi } \\
\text { (g/halyvan/giin) }\end{array}$} & \multirow{2}{*}{ 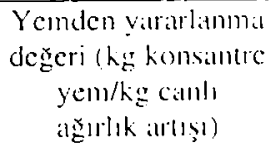 } & \multirow[t]{2}{*}{ 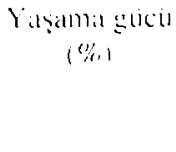 } \\
\hline & & $x$ & & $S x$ & $x$ & $S x$ & & & \\
\hline 3 & 71 & $2.550)$ & \pm & 0.05 & & & $\because$ & & 97.26 \\
\hline 4 & 66 & 3440 & \pm & 0.188 & $126.58 \pm$ & 5.51 & 140.001 & 1.11 & 90.11 \\
\hline 5 & 60 & 4350 & \pm & 0.11 & $130.00 \pm$ & 5.93 & 210.000 & $1.6 ?$ & 90.41 \\
\hline 6 & 66 & 5460 & \pm & 0.13 & $158.98 \pm$ & 5.96 & 259.000 & 1.65 & 90.41 \\
\hline 7 & 66 & 6010 & \pm & 0.15 & $163.66 \pm$ & 5.94 & $3(1) 7.50$ & 1.87 & 90.41 \\
\hline 8 & 65 & 7550 & \pm & 0.17 & $133.82 \pm$ & 4.63 & 368.50 & 2.74 & 89.14 \\
\hline ) & 6.5 & 8470 & \pm & 0.18 & $131.85 \pm$ & 4.55 & 428.00 & 3.26 & 89.114 \\
\hline 10 & $6 ?$ & 9260 & \pm & 0.20 & $103.94 \pm$ & 0.29 & 482.00 & 4.62 & 84.93 \\
\hline 11 & 62 & 9980 & \pm & 0.22 & (i) $2.14 \pm$ & 6.17 & 547.00 & 5.39 & 84.93 \\
\hline 12 & 62 & 1080 & \pm & 0.25 & $120.44 \pm$ & 6.95 & 608.00 & 5.17 & 84.93 \\
\hline
\end{tabular}

$\because=3$ ve 4 . hat talauda civciviere kabal yem verilmemiştir. 


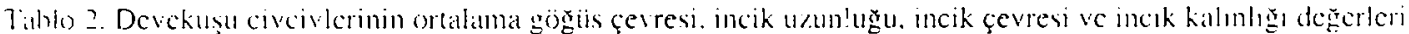

rable 2. The mein values of circumlerence of chest. the length. circumference and thickness of metaltatsus ol ostrich shichs

\begin{tabular}{|c|c|c|c|c|c|c|c|c|c|c|c|c|c|}
\hline \multirow[t]{2}{*}{$\begin{array}{l}\text { Yats } \\
\text { (hiltial) }\end{array}$} & \multirow[b]{2}{*}{11} & \multicolumn{3}{|c|}{$\begin{array}{c}\text { (joggiv f̧curcsi } \\
(\mathrm{cm})\end{array}$} & \multicolumn{3}{|c|}{$\begin{array}{l}\text { lncik uz.un'.ugu } \\
(\mathrm{cm})\end{array}$} & \multicolumn{3}{|c|}{$\begin{array}{c}\text { Incik f̧ckrcsi } \\
\text { (cm) }\end{array}$} & \multicolumn{3}{|c|}{$\begin{array}{c}\text { lucke hilunlus } \\
\text { (mm) }\end{array}$} \\
\hline & & $x$ & & $S x$ & $x$ & & $\mathrm{Sx}$ & $x$ & & $\mathrm{Sx}$ & $x$ & & $S x$ \\
\hline 3 & 71 & 37.75 & \pm & 0.29 & 12.28 & \pm & 0.11 & 5.29 & \pm & 0.05 & 1.3 .27 & \pm & 0.17 \\
\hline 4 & 60 & 41.12 & \pm & 0.45 & 13.88 & \pm & 0.14 & 5.58 & \pm & 0.06 & $1+.08$ & \pm & 11.18 \\
\hline 5 & 66 & 44.80 & \pm & 0.48 & 14.57 & \pm & 0.18 & 5.80 & \pm & 0.07 & 14.8 .5 & \pm & 0.19 \\
\hline 6 & 66 & +8.10 & \pm & 0.50 & 17.22 & \pm & 0.23 & 6.31 & \pm & 0.07 & 1.5 .59 & \pm & 11.19 \\
\hline 7 & 66 & 51.23 & \pm & 0.54 & 18.72 & \pm & 0.25 & 6.75 & \pm & 0.08 & 10.40 & \pm & 11.20 \\
\hline$S$ & 6.5 & 53.54 & \pm & $01.5 !$ & 20.11 & \pm & 0.25 & 7.17 & \pm & 0.09 & 17.16 & \pm & 1). 20 \\
\hline$\varphi$ & 65 & 55.72 & \pm & 0.50 & 21.67 & \pm & 0.27 & 7.58 & \pm & 0.09 & 17.85 & \pm & 0.19 \\
\hline 10 & 62 & 57.64 & \pm & 1).52 & 22.70 & \pm & $1) .29$ & 7.86 & \pm & 0.119 & 18.67 & \pm & 0.21 \\
\hline 11 & 62 & 59.42 & \pm & 01.53 & 23.70 & \pm & 0.28 & 8.11 & \pm & 0.09 & 19.47 & \pm & (1).22 \\
\hline 12 & 62 & 61.32 & \pm & 01.55 & $24.60)$ & \pm & 0.29 & 8.22 & \pm & 0.019 & 20.33 & \pm & 1). 24 \\
\hline
\end{tabular}
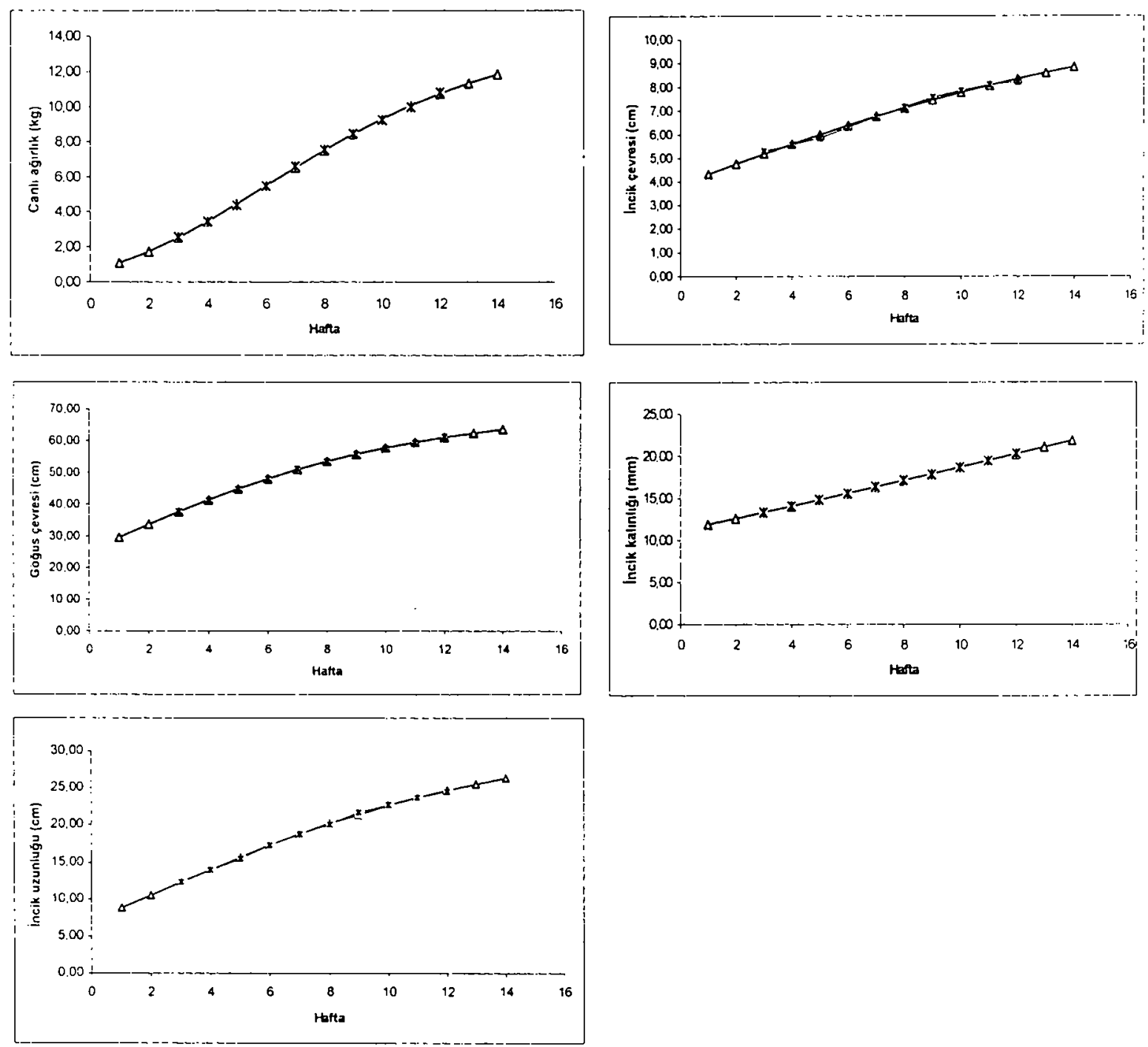

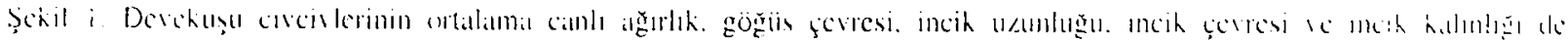
serlerinden clde edilen hiyime exrileri.

Figure 1. The growth curves of ostrich chicks in respect of mean body weight, circumference of chest. the Icngh. circumlerche and thickness of inclatarsus 


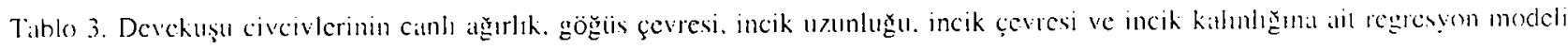
somecliart.

Tible 3. The esults of regression model in respect to body weight. circumference of chest. the length. circumference and thich ness al mctittirsus of ostrich chicks

\begin{tabular}{|c|c|c|c|c|c|c|c|c|}
\hline \multirow[t]{2}{*}{ Orcllik } & \multicolumn{6}{|c|}{ Rcgresyon katsityıliarı } & \multirow{2}{*}{$\begin{array}{c}\text { Belintme katsilym } \\
\left(R^{\prime}\right)\end{array}$} & \multirow{2}{*}{$\begin{array}{l}\text { Hallat killeles } \\
\text { ontitamids }\end{array}$} \\
\hline & 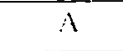 & $\mathrm{Sx}$ & $\mathrm{B}$ & $\mathrm{Sx}$ & C. & $S x$ & & \\
\hline Canll a dorlik & $14.52(1) 4$ & 0.3817 & 0.1958 & 0.0076 & 5.8657 & 0.1504 & 11.90952 & $(1.0)(050)$ \\
\hline Goğtis çerresi & 70.5385 & 0.9738 & 0.1642 & $0 .(x) 73$ & 0.1688 & $0.06(1) 0$ & 10.99447 & $11.11+228$ \\
\hline lncik แrunlugisu & 31.5260 & 0.7674 & 0.1508 & 0.0076 & 2.6611 & 0.1308 & 0.90943 & 0.03 .300 \\
\hline Incih çevresi & 11.3187 & 1.4928 & 0.1046 & 0.028 .3 & 0.6347 & 0.8877 & 0.99160 & $(1.01) 2+3$ \\
\hline lncik katimligl & 55.9298 & 8.7555 & 0.0384 & $0.0(150$ & 12.3739 & 4.0336 & 0.99072 & $11 .(1)(1) 5$ \\
\hline
\end{tabular}

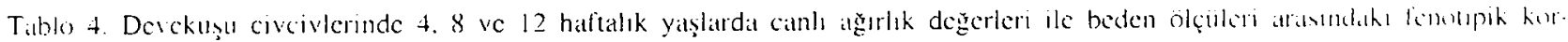
relasyonlar.

Tilble 4. The phenolypic correlations hetween body weights and body measurements at 4.8 and 12 wecks of age in wentich chuck

\begin{tabular}{|c|c|c|c|c|c|c|c|c|c|c|}
\hline \multirow[b]{2}{*}{ Orcllih } & \multicolumn{9}{|c|}{$\mathrm{Canl}$ a a } & \multirow[b]{2}{*}{ 12. hallia } \\
\hline & 3. hattit & 4. hatlia & 5. haftil & 6. hista & 7. haflat & 8. hafta & 9. haffa & 10. hatia & 11. hatlit & \\
\hline \multicolumn{11}{|l|}{ Callll a a grllik } \\
\hline 4. hallit & 0.896 & - & 0.954 & $0.9(17$ & 0.827 & 0.846 & 0.842 & 0.809 & 11.762 & 0.694 \\
\hline 8. hallia & 0.571 & 0.578 & 0.566 & 0.968 & 0.982 & - & 0.986 & 0.725 & 0.7017 & $0.67+$ \\
\hline 12. hatlat & 0.599 & 0.699 & 0.748 & 0.827 & 0.844 & 0.870 & 0.804 & 0.706 & $(1.9) \times 5$ & - \\
\hline \multicolumn{11}{|c|}{ Gog gus ceveresi } \\
\hline 4. hattia & 0.567 & 0.525 & (). 483 & 0.496 & 0.496 & 0.492 & 0.527 & $0.54 t$ & 0.522 & $(1 .+4) 3$ \\
\hline 8. haftat & 0.571 & 0.578 & 0.566 & 0.639 & 0.666 & $0.70) 7$ & 0.717 & 0.725 & $0.70) ?$ & 0.674 \\
\hline 12. halfia & 0.576 & 0.609 & 0. 598 & 0.677 & 0.700 & 0.727 & 0.723 & $0.7+7$ & 0.732 & 11.715 \\
\hline \multicolumn{11}{|l|}{ Incih çeveresi } \\
\hline 4. Inaflat & 0.737 & 0.826 & 0.833 & 0.860 & 0.835 & 0.834 & 0.809 & 0.810 & 0.782 & 11.720 \\
\hline 8. hitlit & 0.543 & 0.647 & 0.712 & 0.783 & 0.795 & 0.795 & 0.817 & 0.808 & 11787 & 0.730 \\
\hline I 2. hallit & 0.656 & 1). 4.56 & 0.557 & 0.597 & 0.677 & 0.70() & 0.727 & 0.724 & $0 .(047$ & 11.650 \\
\hline \multicolumn{11}{|c|}{ Incih w\%unlušnu } \\
\hline 4. hallia & 0.723 & 0.725 & 0.714 & 0.715 & 0.670 & 0.680 & 0.673 & 0.652 & 0.621 & 11.562 \\
\hline$x$ hallat & 0.636 & 0.745 & (1).777 & 0.813 & 0.788 & 0.810 & 0.807 & 0.8014 & 10.782 & 11.727 \\
\hline 12. haffit & 0.621 & 0.752 & 0.795 & 0.795 & 0.753 & 0.773 & 0.765 & 10.781 & 0.768 & 0.723 \\
\hline \multicolumn{11}{|c|}{ Incik kollnnlığ } \\
\hline 4. halla & 0.699 & 0.695 & (1.639 & 0.628 & 0.580 & 0.611 & 0.624 & 0.577 & 0.529 & $11 .+(x)$ \\
\hline 8. haftia & $0.706)$ & 0.768 & $0.7+1)$ & 0.780 & 0.757 & 0.774 & 0.768 & 0.738 & 0.695 & 0.6 .30 \\
\hline 12. hafftit & 0.587 & 0.677 & 0.659 & 0.717 & 0.719 & 0.723 & 0.711 & 0.718 & 0.699 & $0.6(0)$ \\
\hline
\end{tabular}

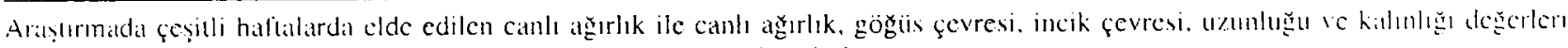

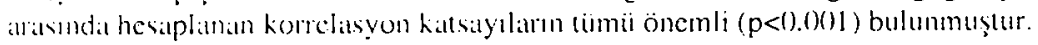

Bu araş̧umada. civcivlerin 4.8 ve 12 haftalıktaki gọğtis f̧evresi. incik umunluğu. incik çevresi ve incik kalmlığ değgerleri ile 3-12. haftalardaki canlı ağırlık degerleri arasunda hesaplanan fenotipik korrelasyonlar Tablo 4 de verilniştir. Hesaplanan korrelasyonlarm tümij öncmli $(\mathrm{p}<0.001)$ bulunnuşır

\section{Tartışma ve Sonuç}

Bu araşturmada 3. 4. 5. 6 ve 7. haftalarda canlı ağ lik için 2550, 3440, 4350, 5460) ve 6610 g. ortalama günliik canlı ağıllık artışı için 126.58, 130.0, 158.98 ve 163.669 olarak elde edilen degerler. Decming ve ark. (12) mun devekuşu civcivleri için 5 haftalık yaşta $4000 \mathrm{~g}$, Decming ve Ayres (10)' in 4 haftalık yaşta $3695 \mathrm{~g}$, Smith ve ark. (26)'nın 4 haftalık yaşla 4000 g we Roth (21) "un 3-7 haftalık yaşlarda sırası ile 2.5. 3.0. 4.0.5.0 ve 7.0 kg olarak bildirdikleri canlı ağ ve ark. (26)'nın 4 haftahk yaşta ortalama $105.0 \cong$ olarak bildirdikleri günliik canl ağırlık artış değerleriyle hen\%el bulunmuşııır.

Bu araşturmadi 8.9.10.11 ve 12. haftalarda cianlı ağarlık için 7550. 8470).9260.9980 ve l(1820) g ve or talama giinliik canlı ağılık artış için 1.33.82. 1.31.85. 103.94, 102.14 ve 120.44 g olarak elde edilen de gerice Gonzales (17) in 3 ayllk civcivler için hildirdiğ $11-14 \mathrm{~kg}$ değerlerine yakm iken. Smith ve ark. (26)'mun 8 ve 12 haltalık civcivler için bildirdiğ 11000 ve 19500 @ canlı a a lık ile 2.33 ve 28.3 g ortalama guinlijk camlı ağalık arlıs 
değerlerinden: Roth (21) un 8 haftalık için bildirdiği 10.0 ko de degerinten daha diişükıür. Bu durum sözü edilen araşImelarm civcivere verdikleri rasyonlarm \%24 protein içermesine ve çevresel laktörlere bağlamabilir. Bu araşImmadaki civcivlerin büytituilduğä dönemde çevre s1-

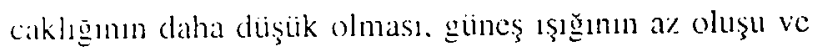
havia koşullarmm elverişsiz olması gibi nedenler büyumeyi olumsuz ctkilemiş olabilir (15.16).

Araşurmada kurulan regresyon modelinin (Gomperl\% modeli) bijyume egrrisini lanmlama derecesi oldukçal yiiksck (R2=0.9995) bulunmuşưr (Şekil 1). Bu da bivaime modelinin canlı ağırlğg onemli duzeyde tamunladlğgnı gösternekledir. Mushi ve ark. (20). Smith ve ark. (26) ve Cilliers ve ark. (8) da benzer somuçlar bildirmişlerdir.

Decming ve ark. (11)'nun bildirdiği gibi bu araşurmada da civcivlerde canlı ağırlık yönünden geniş bir varịasyon görüimuiş̧ür. Bu araşırmada 3 haftalıktan 3 aylığ kadar küçiik civcivlerin diğerlerine göre hep daha küçiik kaldıklan göruilmiışıiir. Benzer bulg̣ular Deening ve Ayres (10) ile Smith ve ark. (26) tarafundan da bildirilmuşur. Devekuşu civeivlerinin buiyümesinde cinsigetin elkili olduğu ve dişilerin erkeklere göre önemli diizeyde daha hı\%h büyüidigği rapor edilmiştir (11). Bu çalısmada, cinsiyeı tayin edilmemiş ancak grup erkek-disi karşsk olarak thal edilmişlir. Ayruca, deneme süresince tiim civcivler birlikle lutulmuşır. Küçük civcivlerin hüyük civcivlerle birlikıe tutulmalan. böylece yem ve su alımı smasında veya gecinirken küçük civcivlerin iri civcivler tarafindan engellenmiş olması gelişmelerini olumsul etkilcmiş olabilir (10,20).

Bu araşurmada civcivlerin günün önemli bir kısmın gexinerck. kiiçük lalş ve benzeri maddeleri arayarak geçirdikluri gơzlenmiştir (7.13.17.20). Bu davranı̧ devekuşu civciveri için doğal olmakla beraber, fazla miklarda yabanc cisim yiyen civcivlcrin yedikleri yabanc1 cisinler ön mideyi doldurarak büyüme hızını olumsuz etkilemiş olabilir. Bubier ve ark. (7) bu tip davranışların stres ile artığın bildirmektedirłer. Bu çalışmada. hayvanlar optimal şatlarda ve temiz alanlarda tutulmuş ve stres oluşıturacak uygulanalardan kaçınılmıştır, ancak Adams ve Revell (1) devekuşu civcivlerinin strese çok duyarlı olduklarm ve hatta civcivlerin ebeveynlerinden ayn kaldıkların hissetmelerinin bile önenli bir stes faklörii olduğunu ifade cemekıdedirler.

Araşurmada 16 güinlük 73 adet devekuşu civcivinden 1 tanesi nakil slrasında, 1 lanesi de geldikten iki gün sonra ijlmüş̧ür. Araşturmada yaşama guicui tüm civeivler ïeriuden ele alınnuş ve 3 haftalıkıa yaşama guicii $\% 97.27$ olarik hesaplanmışur. Dördünciu haftada 5 adet, 7. haf-
Lada 1 adet ve 10. haftada 3 adel olnlak izere Ioplam II adet civciv ölmüş̧ür. Dördüncii haftada ïlen civcivlerden

2 tanesi genel durum bozukluğu gösterdikion homen sonra ölmiiş. 3 tanesinde ise topallama ve ayak problenıleri göruilmiş̧tiir. On haftalık yaştal ise halra is caklığımın aniden diişmesine hağlı olarak kssa sureli de olsa kapalı gèinne alanında iken üşütülen civeivlerden ? hayvanda genel durum bonkkluğu görüilmuis we daha sonraki birkạ̧ güin içerisinde ölmiiş̧erdir. Gencl olarak. bacak problemlerj göriilen civcivler harliç. olen civcivler küçiik ve zayıl yapılı civejvler olmuşıır. Bu durum. zayıl yapılı civcivlerin daha dayanksi\% olduğunu diişündümekledir. Deeming ve Ayres (10) de kuluçkadian çıkışta küçük ve rayıf olan civeriverde yaşăma güiciniun düşük olduğunu bildirmişlerdir.

Bu çalışmada 3 aylık yaşama gaicui \% \% 84.93 hulunmuşlur. Bu değger Sluis (25). Sell (23). Smith ve ark. (26). Deeming ve ark. (11) 'nun bildirdiğ değerlerden dahat yiuksek olup Mushi ve ark. (19)'nu bildirdiği "85 degerine benzencktedir. Bu bilg̈ter ve antọtmada clde edilen yaşama güici değerleri Belçika dan Lşak ili koşullarına getirilerek yetiştirilen derekuşu civerilerinin yal şama guiciniin normal diizeyde olduğunu göstermekledir. Calışmada ölen 11 adet civcivin 4 lanesinde alyak ve parmak problemleri göriilnibştir. Y ïksck proteinli yemlerle besleme ve hizl biiyüme $(2,18.26)$. cozersiz yelersizliğ (10,11,19,20), hazs hastaliklar ve zehirtenmeler (26) ile yaş $(1,7,19)$ gibi laktörler ayak ve parmak problemkrinin oluşumunu etkilencktedir. Eg/ersi\% eksikliğine bağlı ayak problemleri broyler civcivleri için de bildirilmiştir (26.28). Mushi ve ark. (19) lopallama ve bacak anormallikleri nedeniyle ölüm orammn \%15.6 orannda gerçekleşliğini ortaya koymuşlardır. Bu araşırmata ayak problemlerinin yol açtığı ölïm oranı daha duişïk olmus ve \%5.63 bulunmuştur. Deneme süresince circis hölnesi ve gezinme alanlarmn temiz ve kuru olmasma özen gosterilmesinin ve civcivlerin 2 ayliktan sombaki hijyime hlzunın nispeten daha yavaş olmasının ayak ve parmak problemlerinin daha az göriilmesi yöniinde olumlu eıki yaptığ düşünülmektedir $(11,28)$.

Bu araşurmada 3-8 haftalık dïnem jẹin ckde edilen yemolen yararlanma degeri alym dönem için bildirilen 3.47 ve $3.24 \mathrm{~kg}$ konsantre yend $\mathrm{kg}$ canls alghllk allis değerlerinden daha diişüukıiur (5.21). Uç̧-12 haftalık dïnem için elde edilen 3.07 yemden yararlanma des̆geri ise Smith ve ark. (26)'nu 0-4 aylık dönem if̧in yinc aym sekilde hesaplannış olan $2.0 \mathrm{~kg}$ değgrinden daha yiksekıir. $\mathrm{Bu}$ araşturıcıların bildirdiğ yemdeki ham protein dii. zeyinin yüksek olmasi yemden yararlammal degerinin daha iyi olmasına neden olmuş olabilir. 
Civcivlerin yaşı ile hirlikle yemden yararlanma değerninin de büyüdüğ̈i görülmckledir. Bu durum yaşla birlikle yemlerle alman melabolik encrjiden yararlanma düeyinin diş̧nesi ile açıklanabilir. Nitekim. Snith ve ark. (26) canlı ağırliklan $0.3-1.2 \mathrm{~kg}$ arasındaki civcivlerde metabolik encrinin kullanılma değgerinin 0.52 iken 70 $\mathrm{kg}$ 'din yiiksck canlı a olduğunu bildirmişlerdir.

Bu araştumada goğgis f̧evresi, incik u\%unluğ ve çevresi değerleri canl ağgrliğa benzer bir durum göslermis, 10 ve 11. haftalardan itibaren beden ölçülerinin arlıs hızında a\% da olșa düşïş görülmüiştür. Ancak, incik kalınlığındaki arış hııında düşme olmamıştır. Smith ve alk. (26) gogguis genişliğini 4, 8 ve 12. haftalıkta sırası ilc 44. 62 ve $72 \mathrm{~cm}$ olarak bildirmişlerdir. Canlı ağırlıkta olduğu gibi bu araşumala elde edilen gögüus çevesi degerleri de Smith ve ark. (26) mun bildirdiği değerlere 4 halfiada elde edilen $41.12 \mathrm{~cm}$ değeri benzerlik göstermiş, ancak sonraki dönemlerde 53.54. $61.32 \mathrm{~cm}$ ile daha diişik kalmuşur. Bu durum da göğiis genişliği ile canh a ğ̣ılık arasında yuiksek ilişki olduğunu göstermektedir. Incik uzunluğgundaki arlış 11. haftalığa kadar hızlı iken daha sonra daha yavaşlamışır. Bu hulgu Mushi ve ark. (20) nun bulgular ile benzerlik göstermekledir. Bu araşIrmada da 4 . 8 ve 12 haflahk beden ölçüleri ile canlı ağ korrelasyonlar hesaplanmışır. Deeming ve ark. (12) da ben\%er sonuçląr bildirmişlerdir. Bu konu ile ilgili olarak Mushi ve ark. (20) da canh ağılıkla incik (metatarsus) urunluğu arasında $0.97 \%$ lik bir korrelasyon olduğunu rapor emişlerdir.

Sonuç olarak. Belçika dan getirilerek Uşak ili koşullarında yelişlirilen ve 3 aylığa kadar büüumeleri incelenen devekuşu civcivlerinde. büyümenin 6 ve 7. haflalarda en hrzlı olduğu. ikj ayliktan itibaren biraz yavaşladiğı: yaşama gücunüin yüksck olduğu; ayak ve parmak problemlerine bağh ölümlerin ise az olduğu; gioğüs çevresi. incik uzunluğu. incik çevresi ve incik kalunlığ ölçülerrinin canlı ağırlık lahmininde kullamlabileceğj ve civcjvlerin canlı ağırlıklarına göre aymlarak buiyütülmelerinin daha iyi olacağı kanaatinc varılmuşur

\section{Kaynaklar}

1. Adanıs, J, Revell BJ (2()(x)): Ostrich Farming:-A Rewiev" and Fectsibilin Study of Opportunities in the EU. School of Management. Harper Adams University College, Newport. Shropshirc. TFlo8NB. UK. Erişim:|http//www.mluri.sari. ac.uk/ mi36/f casibility/ostrich.huml.

2. Anonim (1994): Ostrich. An Introduction to the Ostrich Industhn: Americiln Ostrich Association. USA.
3. Anonim (1996): Ostrich Guide. Furalton Furcpeill Ralltc Consultant. Belgium.

4. Anonim (1997): Ostrich Farming Informallion Kul. Austratian Ostrich Association. Austrillit

5. Anonim (20)(1)): Ostrich Prodution. Brisim: |hup/wuw. farminfo.org/exotic livestock/ostrich-1m.tillm/.

6. Anonim (2000): Commercial Ostrich Production. North Carolina Cooperitive Extension Service. North Citrolinat State Universily College of Agriculutire and Life Scichee Poultry Science Facts. Ensim: hup: /Awwwecsnesucdut depts/poulsci/techinfo/4Fact $13 . \mathrm{htm}$.

7. Bubier NE, Lambert MS, Deening D)( Ayres IJI., Sibly RM (1996): Time budiget and colone preferences (with specticic reference of feedins) of andich Struthio camelus) chicks in captivin: Bril Poultry Sci, 37. 547-551

8. Cilliers S, Preez JI), Marity J. Hayes J (1995): Gronth curres of ostriches (Struthio camelus) from outhshomm in South Africa. Anim Sci. 61. 101-164. Erism:|hup/suww. ncbi.nlm.nih gov./PubMed.Abstracil.

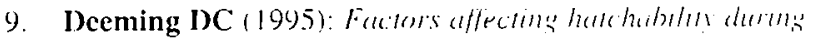
commercial incuthation of ostrich (Swathio comellus; ess.'s Brit Poultry Sci. 36. 51-65.

10. Deeming DC, Ayres L (1994): Fucters affecturs the rate of growth of ostrich (Struthio-comelus) ahicks in captivits Vel Rec. 135. 617-622

11. Deeming D, Ayres L, Ayres F (1993): (Oherencetion on the commercial prodaction of ostrich (Struthio amelus) in the United Kingdom: rearing of chickis. Vet Rec. 132. 627-631

12. Deeming DC. Sibly RM, Magole IJ, (1996) Lrrimution of the weight and body condition of ostriches i Struthio at melus) from body measurements. Vet Rec. 139. 2111-213

13. Degen A, Kam M, Rosenstrauch $\mathbf{\Lambda}$ (1989): Time-(ctirat budget of ostriches (Struthio comelusi offered concentrate feed in oudon pens. App Anim Behiv Sci. 22. 347-358

14. Degen A, Kam M, Rosenstrauch A, Plavnik 1 (|99)).

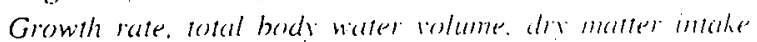
and water consumption of domesticated ostruthes struthion (amelus). Anim Prod. 52. 225-232.

15. Du Pere JJ, Jarvis MSF, Capotos D. Kock JD) (| (9) 2): A note on srowth curves for the estrich (Strution camelus) Anim Prod, 34. 15()-152.

16. Dyce KM, Sack WO, Wensing C.J(F (1996): Teubouk of Veterinary Anatom. 2nd cd. WB Salunders Company. New York.

17. Gonzalez V (1992): Big business in bis birds Workd $P_{0}$ ultry. 8. 8-9.

18. Jefferey JS (200)0): Extension Vetermarian Texas $A_{i:}$ riculural Extension Service. The Texis A and M University Systcm. Erişim:|http//www.g̈:lllu.timu.chlu./ratitc7 ostrich.htmil|.

19. Mushi EZ, Binra MG, Chabo RG, Isa Jl, Plutiti MS (1999): Limb deformities of farmed ostrich i Struthio camelus) chicks in Borswema. Trop Anin Hcilth Prod. 31 397.4(14. Erisim: Thup//wwu.nchi.nlm.nib.gov/Pub.Med. Abstracll.

2(). Mushi FZ, Isa JH, Chabo R(;, Segaise 'T"I (199) Growth rate of ostrich (Strutios camelass) chichs umeter in tensive management in Botswana. Trop Amm Health Prod 30, 197-203. Erişim: |hıp//www.nchi.nlm.nil, gov:/Pub Med. Abstractl. 
21. Roth L (20)(0)): Introduction to the Ratite Indusiry and the Use of Fastrack Directed-fied Microbial Products. Resecarch and Development Conklin. Co Inc. Erişim:|http/l uscrs./4.net/asonc/Ratites.huml|.

22. Schalkwyk S.J, Clocte WP, Kock JA (1996): Repeatahilit) and phenorypic correlations for bordy weight and reproduction in commercial ostrich breeding pairs. Bric Poultiry Sci. 37. 953-962.

23. Sell R (2006): Ostrich. Department of Agriculural Ecomomics. NDSU Scrics. North Dakolit. A Dwinght (Ed). Farm Mamiagement Speciatist NDSL: Extension Service. Erișim: |http//www.ext.noditk.edu/extpubs/alt-idg/ostrichhun|.

24. Shonawany MM (1996): Ostrich farming is an ancient busmess. Misset World Poultry. 12. 59-63.

25. Sluis IV (1095): Beloium ostrich producers group ready for markening. Misise World Poultry. 11.51-55.

26. Smith W, Cilliers SC, Mellett FD, Van Schalkwyk S.J (2000): Ostrich Production-A South African Perspective.
Nottingham Universily Press. UK. In: Bintectmology in the Feed Industry. Proceedings Alltech's 1 th Annual Sympo sium. May 8-11). Lexinglon. KY.

27. Tekerli M (1999): Ihi berive istincuden dosisu dentleninden imerpolasion $\mathrm{C}^{++}$bilgisayal programs. Alyon

28. Thorp BH, Duff SR (1988): Lffects of elete tise cin the lascular pattern in the bone exremities of hroblet fowl Rer

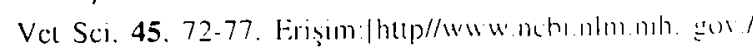
PubMed.Absuatct).

Gelis larihi: 26.3.2001/ Kabul turiht : 9.1.21\%i2

Yazışma adresi:

Yrd. Dogc. Di: Zehra Akmel

Afion Kocatepe Universitesi. Veteriner Fukillesi

Zootekni Anabilim Dall

ANS Kampisii-Afion

Eimail:zehraakini@ (@)tmail com 